\title{
A board game proposal for teaching informatics related topics in Early Childhood Education.
}

\author{
Tharrenos Bratitsis*, Anna Kontovounisiou**, and Maria Kiriazoglou*** \\ University of Western Macedonia, Greece
}

\begin{abstract}
This paper presents an idea of a board game designed for teaching informatics related topics to kindergarteners, as part of an undergraduate thesis. The idea emerged through a course about game-based learning and popular board game ideas were examined. Based on a brainstorming session, the appropriate format of the board was selected. Then, the topics were selected, addressing the issue of internet use by young children. The subtopics identified were that of safety while accessing the internet, proper computer use, technological matters and functional potential (all explained in detail in the paper). The game idea, mechanics and design are presented in this paper.
\end{abstract}

\section{Introduction}

Game utilization is a field of growing attention over the past few years, whether digital or not. This relies on the idea that in contemporary education requires from the students to be actively engaged and overall learning should be fun. Card or board games, but even digital ones transform the learning process form an activity which is often perceived as mandatory labor into a recreational activity [1], [2], [3]. Games facilitate students' active learning, namely make them become responsible for their learning. Especially in the case of Educational Board Games (EBG) students' knowledge may be enhanced and competencies can be cultivated even without the supervision of a teacher [4]. Game playing has been found to support the development of students' critical thinking, problem solving competencies, oral and written communication skills, and information analyzing abilities [5].

Game utilization for educational purposes has been well documented [6], [7]. Evidence has been provided for many educational levels and disciplines [8], [9], [10], [11]. As can be seen from the indicative citations that refers to many kinds of games such as digital games, online games, board games or even kinesthetic games. The focus of this paper is on board games, a very famous and rather specific category of games. As Helliar at al. [12] claim, board game utilization within the educational process may lead to an interactive learning experience, thus highlighting the added value of such games.

\footnotetext{
* Corresponding author: bratitsis@uowm.gr

** Corresponding author: annak98@hotmail.gr

*** Corresponding author: marikyrg@gmail.com
} 
Following this approach, a board game was designed as part of an undergraduate thesis at the Early Childhood Education Department of the University of Western Macedonia, Greece. The disciplinary area is that of informatics and specifically the required technology for and the use of internet, divided in subsections, as described later in this paper. The game idea and design, including the board, the game mechanics and the game resources are to be described. The paper is structured as follows: A brief literature review supporting game based learning is highlighted. Then, the game is described in detail, as explained in the previous paragraph. Since the game has not been tested already (partially due to the pandemic which totally altered the schooling approach in 2020), the paper concludes with a discussion which also focuses on future research, utilizing this game.

\section{Theoretical Background}

\subsection{Game-based learning}

Christophel [13] argued that teaching should focus on how students should be taught rather that what they should be taught, indicating the way for student-centered learning activities which have gained the center of attention for the research community of the educational sector for many years now. Researchers [14], [15], [16] agree that game utilization in education could positively impact students' learning, whereas studies show that games can enhance learning motivation and students' learning proficiency [17], [18], [19]. Kandroudi et al. [20] identify motivation as a significant factor for the learning process as it promotes engagement. Wlodkowski [21] highlights motivation and will to learn which overcomes in significance learning itself, as they provide the drive for learning. For Gee [14] motivation is the basic element for students and for the sense of learning. Motivation in learning is a way to enhance students with a positive attitude to complete an activity, no matter how difficult and hard it may be [10]

Prensky [23] brought up the opposition between the engaging nature of game playing and the rather painful for the students typical process of learning. Additionally, Garris et al. [24] connected the effectiveness of engagement with that of learning, claiming the games' utilization facilitates reaching such a goal. Brown [25] also argued about learning as not being a result of teaching but merely deriving from an appropriately nurturing environment, which also applies to games.

Gros [26] stresses that a game needs to be also educationally appropriate; just motivation is never enough. Kiili [8] further connects a games' educational benefits through the provision of challenges to a main learning task. Oblinger [27] also argues about the importance of the way a game is used. He supports that learners through games should: a) be engaged with the subject theories, b) acquire knowledge via autonomous and discovery learning, c) cultivate thinking skills, d) learn how to learn (metacognition), e) interact and communicate, and f) operate as active producers of knowledge.

For Kim et al. [28], game playing is similar to problem solving which may also facilitate metacognitive strategies like self-recording, modelling and thinking aloud. This is in accordance to Vygkotsky's sociocultural theory [29] which suggest that learners construct their knowledge through experiential and reflective activities, making meaningful connection with their own experiences, individually or collaboratively.

Thus, overall games are described as being motivating for students and providing opportunities for experiential learning, when used in an appropriate manner. 


\subsection{Board games}

According to Juul [30], a game is a rule-based system with a variable and quantifiable outcome, where different outcomes are assigned different values, the player exerts effort in order to influence the outcome, the player feels attached to the outcome and the consequences of the activity are optional and negotiable". Main elements of the game that contribute to learning are theme of the game, objectives, rules, adaptability to students' competency level and controllability [31].

A game is contextualized by the selected theme [30] which has a significant impact on the players' interest and motivation to become involved. The game goals reflect upon the winning conditions and thus game rules and player motivation [32]. It is also important for a game to have very clear instructions on how to play the game [33]. It is common for players to consult peers for playing a game [34] and thus in-game discussion should be enhanced. Difficulty levels are usually incorporated and generally students want to achieve a game's goals utilizing their skills and knowledge, not pure luck [34] as it makes a game rather boring or occasionally frustrating [33]. A player should be allowed to make decisions within the game, thus gaining control over it [32]. Of course, aesthetics are also important, as a game, especially a board game appeals on the players; eyes first. Lastly, interaction in the form of either competition or collaboration enhances players' motivation [35], as does the required time to play the game which can be a decisive factor for players when investing in a game while feeling engaged.

"Board games are an important tool to provide hands-on and heads-on skill and knowledge development for people of all ages on all subjects. Not only do well-designed games create an engaging atmosphere, they also provide a non-threatening, playful, yet competitive environment in which to focus on content and reinforce and apply learning.", Treher [36] states. The board should be meaningful for the players and acts a visual metaphor, facilitating information connection. Mistakes are welcomed and tightly connected to game mechanics, as they reveal what needs to be learned.

In a board game a board is used, upon which other tangible elements (e.g. pawns or probes) are placed. The positioning of the elements is connected to the overall visualized metaphor and the theme of the game. Players take turns and move on the board, utilizing some mechanism (e.g. by rolling a dice). Then they are required to proceed to actions, as they are described by the game rules. It is important also to highlight the a board game is played through physical presence, so the social aspect of learning is further enhanced through such games, as players are required to sit around the board and socialize, freely occasionally, while also playing and learning.

Overall, board games appear to have some interesting advantages which also include their independence of technological infrastructure and their portability. Thus, in this paper the idea and design of a board game is described (next section) for teaching informatics related topics to Kindergarten children. Similar approaches but for older ages are not very common, but are evident in the literature [37], [38], also addressing other disciplinary areas [12], [11], [39], [40].

\section{Game description}

At the Early Childhood Education Department of the University of Western Macedonia, located in Florina city, Greece, the 3rd year students have the opportunity to select 2 out of 4 available didactics' related courses. One of them concerns didactics of informatics. The students graduate to become mainly Kindergarten teachers. The content of the course regards a theoretical approach for didactics in general and informatics in particular, followed by a practical section in which the students are required to design their own teaching approaches 
for a topic related to the disciplinary area, also following the official curriculum of the Greek Kindergarten. Every year the practical part of the course is decided onsite in collaboration with the attending students, in order to increase engagement and motivation. In the 20192020 academic year, a decision was made to design a board game, following the instructor's (the main author of this paper) proposal.

The idea was to create a board game about a general topic which falls under the informatics discipline. According to the official Greek Curriculum, children at this educational level are supported in order to familiarize themselves with various technologies, but also understand their use and usefulness. Furthermore lately the educational approaches focus on cultivating competences, defined as sets of knowledge, skills and attitudes/values [41]. Utilizing the experience from previous work [42], a similar approach was followed in this case as more appropriate for the defined goal. After a brainstorming session close to the middle of the semester (after all the theoretical aspects of didactics were discussed) a decision was made to focus on internet technologies and uses, taking into account that nowadays children at the age of 4-5 are already internet and smart device users, in some cases heavy users. Thus, the aim was to identify the appropriate knowledge about the corresponding technologies and proper use (including safety matters), the necessary skills and the corresponding attitudes towards internet use (involving the identification of services and their usefulness).

As the brainstorming session revealed distinct subtopics, a consequent discussion reflected upon the experiences of the students involved. It was about the design of the game board, starting from famous entertaining board games. Several games were considered which incorporate categories of actions and/or cards, such as Trivial Pursuit. The instructor already had proposed that the game mechanics should involve various types of questions to be answered or negotiated, following the common approaches of teaching in Kindergarten. Eventually, a proposal was made to rely on the Game of Life board game. In all variations of this game there is one main path (corresponding to a main concept) and attached sub-paths which form closed routes (corresponding to subtopics). As this is a famous board game, a decision was made to follow this approach.

As aforementioned, the main topic chosen was the internet. Overall 4 subtopics were identified: a) safe use, b) proper use, c) functional possibilities, and d) technical/technological issues. The idea was that children should acquire knowledge (what is the internet and what do I need in order to connect and use it), skills (proper use) and attitudes (safe use but also useful functionalities), thus cultivating competences on the topic. The "safe use" subtopic concerns issues like cyberbullying, respecting other internet users, identifying internet fraud, issues related to personal data, etc. The "proper use" subtopic concerns daily hours of internet use depending on the age, body posture when using a computer or a smart device, the connection of internet use with other obligations of a typical student (e.g. one has to complete homework before being allowed to play an online game), etc. The functional possibilities refer to uses of internet. For example a child can talk to the grandparents via teleconferencing, one can buy goods online and perform transactions, news and knowledge can be found online. The last subtopic refers to the electronic devices and other technological issues, such as the need to use and the functionality of a router, the ability to connect through a variety of devices, etc.

Considering the board concept of the original game, the board depicted in Figure 2 was created. It is to be noted that at this point a draft sketch is presented, as explained in the following section.

The board consists of 4 paths (corresponding to the subtopics mentioned in the previous paragraph) and 1 bonus path. Each path comprises in 10 squares (although in the board design they appear more as arrows), except the bonus path which comprises of 8 squares. In Figure 1, they correspond to the outer semi-circle paths and the circle in the middle of the board, accordingly. Moreover there is a deviation comprising in 5 squares attached to each path. 
This allows the player to avoid entering a path and move to another one (inner semi-circle paths). Instead of a dice, the authors decided to use a clock-like spinner which is to be positioned on the lower left corner of the board. The spinner includes the numbers 1 to 3, indicating the number of square the player has to move in each turn. This way, when the player enters a path he/she will be required to stop at least 2 times in order to take action accordingly.
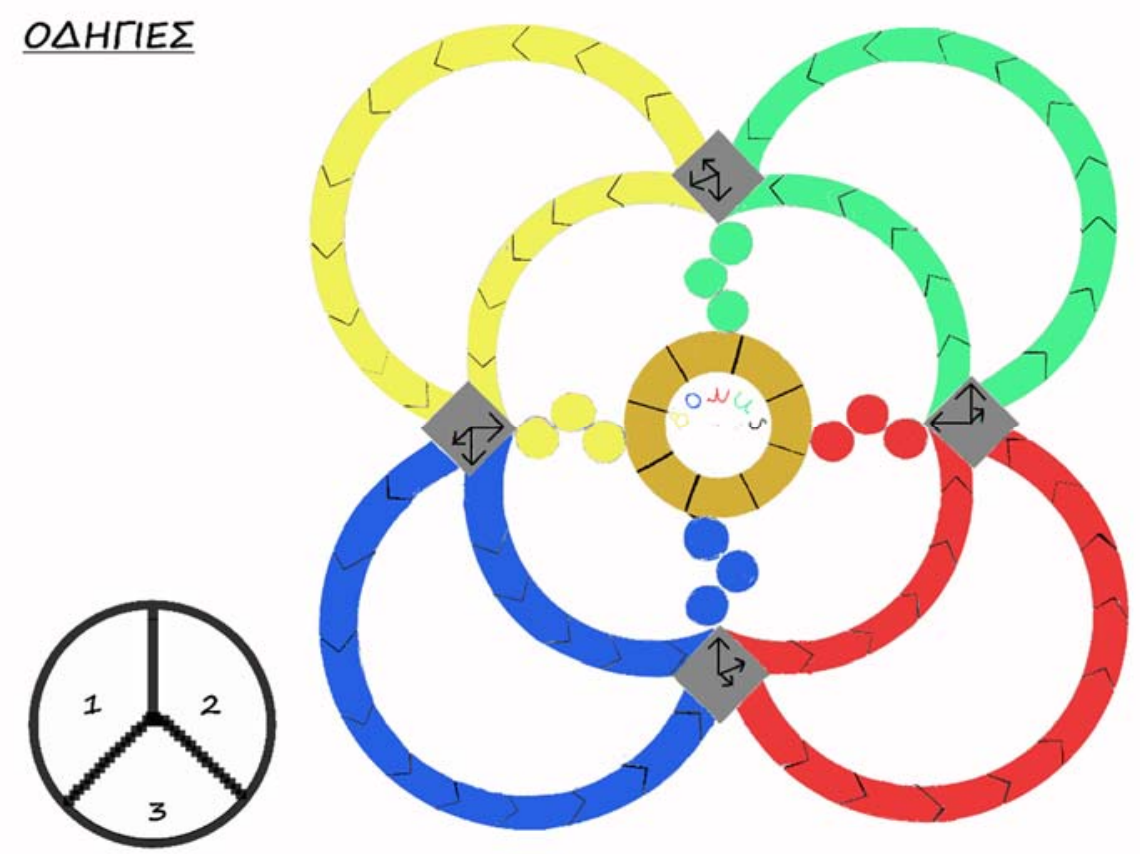

Fig. 1. The board of the proposed game.

The game has been designed so as to be played by 2-4 players. Of course in a classroom setting this can be adjusted to the population of the class by forming 2-4 groups of children who will negotiate and provide the required answer or action when needed. In this first version of the game printed cards containing questions or exercises (explained hereinafter) were also designed. Thus, an adult supervisor is needed to read out the content. The idea of recording the card contents and using embedded QR codes which would lead to audio, image or video files which would form the question was brought up, but due to time limitations and the problems that arose from the pandemic a decision was made to leave that for a next version of the game. Additionally, this would require an internet connection and a smart device for the game to be played, whereas this card-based version could be played anywhere, anytime.

Regarding the game rules, all players turn the spinner in order to decide the sequence in which they would take turns. Each player selects 1 of the 4 path-starting square (indicated with the 3 arrows in Figure 1) and places his/her pawn. The pawns are not yet designed, but the idea is that they will correspond to internet related devices (e.g. tablet, router) and will be created with a $3 \mathrm{~d}$ printer. At the beginning each player is assigned with an inventory of 6 stars. 

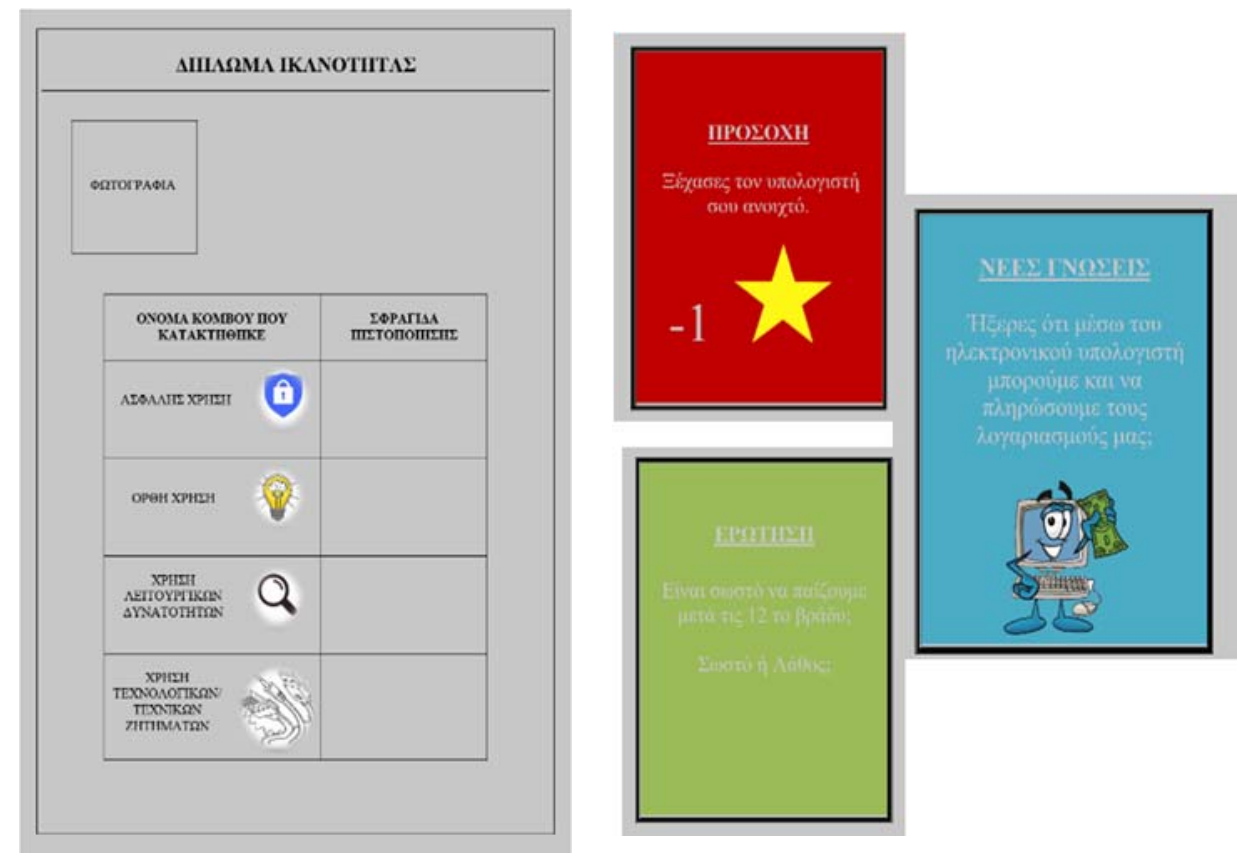

Fig. 2. Certification and action cards.

The aim is for the player to collect 4 stamps which correspond to the 4 paths of the board. The stamps will be imprinted on the certification of Internet Competent User (Figure 2 - left side). In each path, at least 4 squares correspond to advisory cards who lead to gaining or losing stars. An example of such card is the red one in Figure 2 which reads "ATTENTION: you forgot to turn off your computer" and leads to losing 1 star. In order for the player to win the stamp, he/she has to answer to a question (Figure 2 - green card) after a mandatory stop at the end of the corresponding path. In order to "listen to" the question, the player has to "pay" 3 stars and of course he/she has to provide the correct answer. In the example in Figure 2 , the card reads "Is it acceptable to play computer games after 12am? Yes/No". Considering the age of the players, of course the correct answer is No. Other questions are in a multiple choice format. If the player provides the wrong answer, then he/she has to "walk" the corresponding path again from the beginning, after reaching its initial square again. Thus the player has to take turns in order to go around the whole board again.

If the player runs out of stars then he/she is automatically transferred at the beginning of the path he/she is in at the moment. There is the choice of collecting 6 additional stars if the player enters the bonus path, by taking the closest deviation. In order to achieve that, the player has to answer to more difficult questions and he/she can repeat the process as desired. Also, in the inner path which is merely used to allow the players to move around the board and reach their desired sub-path corresponds to the blue cards (Figure 2). These are knowledge cards, read aloud each time the player stops to a square of this central path. The example in Figure 2 reads "NEW KNOWLEDGE: Did you know that through a computer we can pay our bills?" and there is a graphic related with that information (in the example a smiling computer holding some banknotes). These cards are directly connected to the green cards and thus a player is not required to hold all the necessary knowledge before playing the game; the knowledge is embedded in the game through the blue cards and tested through the green ones.

The game is completed when either one or all the players acquire their certification. Of course the sooner one receives the certification, thee better his/her performance is. In the case of 
playing the game in small groups, the teacher can help the children decide on a process of reaching consensus before providing an answer (e.g. they can decide upon a voting process and thus the game becomes rather interdisciplinary).

Reflecting on the game rules described up to this point, it is clear that different strategies can be followed. For example a player can initially try to increase the star inventory and then attempt to collect the stamps. This allows less movement around the board as in the case of lack of stars, one has to follow larger overall routes in order to try again. Having a larger star repository, the player can directly follow the path that leads to the stamp, instead of moving to get more stars and then try again. Another strategy is to move around the inner path in order to "collect knowledge" and then try acquiring the stamps when the player feels confident enough to do so. Thus, there are many way to approach the game and it is the authors' impression that this will motivate the children to play the game repeatedly in order to find the best strategy and achieve a better score (acquire the certification with the least moves possible).

\section{Discussion and further plans}

As explained in this paper, a decision was made to design a board game in order to teach internet related issues to Kindergarten children. After the completion of the course and the draft design which was described in the previous section, two students (co-authors of this paper) decided to follow up on this work and implement a teaching intervention in a typical classroom, as part of their undergraduate thesis. Of course, it is important to mention that the schools' and universities' lockdown due to the pandemic did not allow the refinement of the design and the implementation of the test. The latter is planned for the next school year, depending on how the situation evolves.

Regarding the remaining tasks, the board is at the level of being computer designed but still needs to be printed in a large enough size (not done yet, due to the pandemic). As mentioned, the pawns need to be $3 \mathrm{~d}$ printed. A considerable amount of cards has already been designed (also to be printed). The purpose of the authors is to conduct a small scale survey with teachers and academics in order to examine the appropriateness of the card contents. Then, the game is planned to be tested in at least one classroom, utilizing also worksheets as preand post- tests in order to evaluate the students' knowledge prior and after the intervention. Interviews will be conducted in order to evaluate various aspects of the game. Also, a similar test with adults (e.g. pre- or in- service teachers) is thought to be carried out. Unfortunately, the pandemic didn't allow the design team to work face to face as desired in order to finalize the game elements nor to carry out at least the initial studies for evaluating the designed material. Thus everything is postponed for the forthcoming year (2021) and will be adjusted and reconsidered, depending on the emerging situation.

As for future plans, the authors plan on creating a digital version of the game incorporating QR codes and multimedia material, as explained in the previous section. Other ideas include the construction of an extendable and modular board which would incorporate more than 4 paths if desired. This would allow teachers to work on the informatics topics of their choice, based on their teaching design and strategy. In this manner, the teacher would be able to assemble the corresponding paths and utilize the related action cards for the game to match his/her teaching plans. As it is, the board can support 4 subtopics/paths which can be selected by the teacher, regardless the fact that action cards were designed for internet related topics. An idea to facilitate that is to add a small square inside each path in which a graphics card will be places, corresponding to the same section of the certification to be filled through the game. This graphic (see Figure 2 for example) will also be printed on the back of the red and green cards which correspond to that path/topic. Much later, the digital version could be 
Augmented Reality based and it would be interesting to test such a game in comparison with the non-digital version described in this paper.

\section{References}

1. C.C. Schroeder, New students-New learning styles, Change: The Magazine of Higher Learning, 25(5), 21-26(1993).

2. J. Kirriemuir, A. McFarlane, Literature Review in Games and Learning (Futurelab Series: Futurelab, 2003)

3. L. Bragg, Students' conflicting attitudes toward games as a vehicle for learning mathematics: A methodological dilemma. Mathematics Education Research Journal, 19(1), 29-44 (2007).

4. S. Mostowfia, N. K.Mamaghanib, M. Khorramarb, Designing Playful Learning by Using Educational Board Game for Children In The Age Range of 7-12: (A Case Study: Recycling and Waste Separation Education Board Game), International Journal of Environmental \& Science Education, 11(12), 5453-5476 (2016).

5. V. Alvarez, Engaging Students in the Library through Tabletop Gaming, Knowledge Quest, 45(4), 40-48 (2017).

6. M. Prensky, Digital game based learning. (New York, NY: McGraw Hill, 2001).

7. M. Prensky, Don't bother me, mom, I'm learning! (St. Paul, MN: Paragon House, 2006).

8. K. Kiili, Digital game-based learning: Towards an experiential gaming model, Internet and Higher Education, 8, 13-24 (2004).

9. M.M. Tanner, T.M. Lindquist, Using Monopoly and teams-games-tournaments in accounting education: A cooperative learning teaching resource, Accounting Education, 7(2), 139-162 (1998).

10. J. Elofsson, S. Gustafson, J. Samuelsson, U. Träff, Playing number board games supports 5-year-old children's early mathematical development, The Journal of Mathematical Behavior, 43(2016), 134-147 (2016).

11. B. Hoy, Teaching History With Custom-Built Board Games, Simulation \& Gaming, 49(2), 115-133 (2018).

12. C.V. Helliar, R. Michaelson, D.M. Power, C.D. Sinclair, Using a portfolio management game (Finesse) to teach finance, Accounting Education, 9(1), 37-51 (2000).

13. D.M. Christophel, The relationships among teacher immediacy behaviors, student motivation, and learning, Communication Education, 39(4), 323-340 (1990).

14. J.P. Gee, What video games have to teach us about learning and literacy, Computers in Entertainment (CIE), 1(1), 20-20 (2003).

15. B. Williamson, Computer games, schools, and young people: A re-port for educators on using games for learning. (Futurelab, 2009).

16. D.W. Shaffer, K.R. Squire, R. Halverson, J.P. Gee, Video games and the future of learning, Phi delta kappan, 87(2), 105-111 (2005).

17. M. Ebner, A. Holzinger, Successful implementation of user-centered game based learning in higher education: an example from civil engineering, Computers \& Education, 49(3), 873-890 (2007). 
18. M. Papastergiou, Digital game-based learning in high school computer science education: impact on educational effectiveness and student motivation, Computers \& Education, 52(1), 1-12 (2009).

19. L.C. Wang, M.P. Chen, The effects of game strategy and preference-matching on flow experience and programming performance in game-based learning, Innovations in Education and Teaching International, 47(1), 39-52 (2010).

20. M. Kandroudi, T. Bratitsis, N. Lambropoulos, Pedagogical and immersive design principles in motion-sensing games: demonstration on Altenerville for physics, In proceedings of the 8th European Conference on Games Based Learning. University of Applied Sciences HTW Berlin, 9-10 October 2014, Berlin, Germany (2014).

21. R.J. Wlodkowski, Motivation and teaching: A practical guide. (National Education Association, Washington, DC, 1978).

22. D.A. Cook, A.R. Artino Jr, Motivation to learn: an overview of contemporary theories, Medical education, 50(10), 997-1014 (2016).

23. M. Prensky, The motivation of gameplay: The real twenty-first century learning revolution, On the horizon, 10(1), 5-11 (2002).

24. R. Garris, R. Ahlers, J.E. Driskell, Games, motivation, and learning: A research and practice model, Simulation \& gaming, 33(4), 441-467 (2002).

25. J.S. Brown, Learning in the digital age. In The Internet and the university: Forum, (Washington, DC: Educause, 2001).

26. B. Gros, Digital Games in Education: The Design of Games-Based Learning Environments, Journal of Research on Technology in Education, 40(1), 23-38 (2007).

27. D. Oblinger, Games and learning, Educause Quarterly Magazine, 29(3), 5-7 (2006).

28. B. Kim, H. Park, Y. Baek, Not just fun, but serious strategies: Using meta-cognitive strategies in game-based learning, Computers \& Education, 52(4), 800-810 (2009).

29. L. Vygotsky, Interaction between learning and development, Readings on the development of children, 34-41 (1978).

30. J. Juul, Half-real: Video Games between Real Rules and Fictional Worlds. (Cambridge: MIT Press, 2005).

31. I. Zsoldos-Marchis, I. Design board-games for developing pre-service primary school teachers' mental calculation skills. Proceedings of EDULEARN19 Conference 1-3 July 2019, Palma, Mallorca, Spain (2011).

32. K.A. Wilson, W.L. Bedwell, E.H. Lazarra, E. Salas, C.S. Burke, J.L. Estock, K.L. Orvis, C. Conkey, Relationships between Game Attributes and Learning Outcomes, Simulation \& Gaming, 40(2), 217-266 (2009).

33. J.B. Pornel, Factors that Make Educational Games Engaging to Students, Philippine Journal of Social Sciences and Humanities, 16(2), 1-9 (2011).

34. J.P. Van Staalduinen, Gamers on Games and Gaming Implications for Educational Game Design. PhD thesis, Delft University of Technology (2012).

35. T.W. Malone, M. Lepper, Making learning fun: A taxonomy of intrinsic motivation for learning. In Snow, R.E. \& Farr, M.J. (Eds.), Aptitude learning, and instruction III: Cognitive and affective process analysis. (Hilldale, NJ: Erlaum, 1987).

36. E. Treher, Learning with board games. Tools for learning and retention. (The learning Key, Inc, 2011). 
37. I. Bezáková, J. Heliotis, S. Strout, Board game strategies in introductory computer science. In Proceedings of SIGCSE'13, March 6-9, 2013, Denver, Colorado, USA (2013).

38. K. Tsavara, K. Moeller, M. Ninaus, Training computational thinking through board games: the case of crabs \& turtles, International Journal of Serious Games, 5(2), 25-44 (2018).

39. P. Drake, K. Sung, Teaching introductory programming with popular board game, In Proceedings of the 42nd ACM technical symposium on Computer science education SIGCSE '11, March 2011, Dallas TX USA (2011).

40. B. Taspinar, W. Schmidt, H. Schuhbauer, Gamification in education: a board game approach to knowledge acquisition, Procedia Computer Science, 99, 101-116 (2016).

41. European Union (EU), Recommendation of the European Parliament and of the Council of 18 December 2006 on key competences for lifelong Learning, Official Journal of the European Union, Publications Office of the European Union (2006)

42. T. Bratitsis, Demonstrating Online Game Design and Exploitation for Interdisciplinary Teaching in Primary School through the WeAreEurope Game for EU Citizenship Education. In A. Mikropoulos (ed), Research on e-Learning and ICT in Education. Technological, Pedagogical and Instructional Perspectives, (Springer International, 2018). 